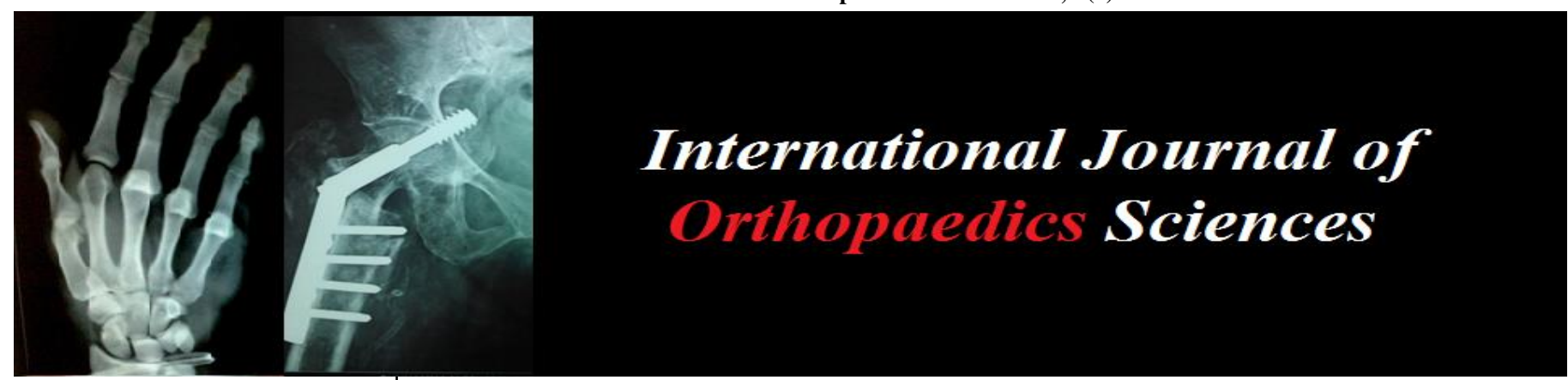

E-ISSN: $2395-1958$

P-ISSN: 2706-6630

IJOS 2020; 6(1): 582-585

(C) 2020 IJOS

www.orthopaper.com

Received: 06-11-2019

Accepted: 10-12-2019

Dr. Kundan Kumar

Dept. of Orthopaedics,

Central Hospital Ramgarh, CCL

Ranchi, Jharkhand, India

\section{Orthopaedic implant removal: An observational analysis on its incidence, indication, socio-economic burden and its complications during and following removal}

\section{Dr. Kundan Kumar}

DOI: https://doi.org/10.22271/ortho.2020.v6.i1k.1929

\begin{abstract}
Fractures around the upper and lower limb is increasing now-a-days due to RTA, active sports and cultural participation and there is a need to fix those fractures using orthopedics implant in order to restore the anatomy of joint and other skeletal anatomic structures. Practice for removal should be thought only for symptomatic patients where the implant is causing socioeconomic burden on life and decreasing the quality of life once the fracture has healed. However the timely removal of orthopedic implants even for asymptomatic patients also has benefit for reducing risk of infection, osteopaeni, refracture and rarely carcinoma. Removal sounds to be a simple procedure but it is an unsolved challenge to an orthopedic an due to its unwanted complication during and after the procedure.
\end{abstract}

Keywords: implant removal, observational, incidence, indication, socio-economic burden

\section{Introduction}

The most common modality of treatment in Orthopedics trauma is ORIF with plate and screw/CRIF with IMIL nail; CC screw; TBW; K wires etc. The removal of orthopedics implant constitutes one of the major operations in bone and joint surgery ${ }^{[1]}$. However there is a controversy regarding when to remove an implant. In children and adolescent it is necessary to remove the implant to avoid growth disturbances, refractors, osteopenia changes and carcinogenic potential ${ }^{[2]}$. There is a also a risk of corrosion and systemic release of chromium, nickel and cobalt ${ }^{[3]}$. There is a socioeconomic burden related to orthopedic implants. There are three components of burden related to surgery-Direct cost, indirect costs psychosocial or intangible loss ${ }^{[4]}$.

Direct cost-Includes implant cost, investigation fee, O.T charge, Doctors fee which is usually reimbursed by govt.

Indirect cost: Loss due to productivity of his life ${ }^{[5-7]}$

Intangible costs ${ }^{[8-10]}$. IT refers to deterioration of the patients quality of life as they have to depend on family due to functional loss of limb.

Every implant removal is challenging and is full of complication such as mechanical failures, pain, infection ${ }^{[11,12]}$ and bone refracture. Removal is a surgically planned procedure usually done due to pain, infections, exposed implants or at patients request.

\section{Materials and Methods}

This study was conducted in Dept. of Orthopedics', K.R. Hospital Mysore between December 2017 TO December 2018. Ethical committee clearance was taken. Routine investigations and ESR, CRP was done. No special investigations such as CT scan or MRI were done. Patients were divided into 2 groups: MIRN (Medical indication for removal) and NMIR (non medical indication for removal). Post operatively patient was allowed to stay for 6 days following surgery urgery was done on the second day of admission after anesthetic clearance.
Corresponding Author: Dr. Kundan Kumar Dept. of Orthopaedics, Central Hospital Ramgarh, CCL Ranchi, Jharkhand, India 


\section{Inclusion criteria}

1. Complete union

2. Infected implant in situ

3. Exposed implants

\section{Exclusion criteria}

1. Elderly patients above 90 years of age

2. Fractures with infected implants but not united

MIR was defined as: Implant failure, infection, mechanical problems, peri prosthetic fractures, aseptic necrosis, non union, pain with a traceable source.

NMIR was defined as: patients demand without reasonable intention, metro- sensitivity, foreign body sensation, elective implant removal depending on surgeons' choice and pain without a traceable source.

\section{Stastical Analysis}

All the data was entered into Microsoft excel and analyzed by statistical software Pad Prism version 6 for windows. Descriptive statistics of mean and standard deviation were calculated for all continuous and compared using student $-\mathrm{t}$ test. All category variables were analyzed and reported as frequencies and proportions and compared using Fischer's exact test.

\section{Results}

Out of the 30 patients who are fulfilling the inclusion criteria. It was found out of $30,25(87.5 \%)$ male and $5(12.5 \%)$ are female. Mean age of the patient are between 35-45 years. It has been seen that the incidence of removal is twice in men as compared to female ${ }^{[13]}$. Implant removed out of 30 patient are Indication for removal was medical indication and non medical indication, medical indication was $20 / 30(66.5 \%)$ and non medical indication 10(33.3\%).

Table 1: Showing incidence of following implant removal done in K.R hospital form December 2017 to decent 2018

\begin{tabular}{|c|c|c|}
\hline NDCP & 5 & $16.6 \%$ \\
\hline Tibia Imil Nail & 10 & $33.3 \%$ \\
\hline DHS & 5 & $16.6 \%$ \\
\hline PTLCP & 1 & $3.3 \%$ \\
\hline Clavicle Plate & 2 & $6.6 \%$ \\
\hline DER & 1 & $3.3 \%$ \\
\hline TBW & 1 & $3.3 \%$ \\
\hline DFLCP & 5 & $16.6 \%$ \\
\hline
\end{tabular}

Among medical indication for removal, Implant failure include $3(15 \%)$, Infection include $4(70 \%)$ and pain includes $3(15 \%)^{[14-16]}$. Among non medical indication most common indication was patient demand 6/10(60\%) and elective surgery was $4(40 \%)$.

Socioeconomic burden relates with number of working days lost, cost of re - surgery and dependency following surgery. All patient has an average of 6-8 lost of working days and total cost of removal was Rs 8000. Including OT charge, doctors charge, routine investigation, medicine charge was not taken into account.

Among complication out of 30 patient only 2 patient has refracture $(6.6 \%)$, in $1(3.3 \%)$ patient implant was not able to remove due to head of the screw was rounded and $2(6.6 \%)$ patient complaints of post-operative pain.

Table 2: Table showing patient operated area with its indication, complication, economic burden in terms of number of days lost, procedure failure with its cause

\begin{tabular}{|c|c|c|c|c|c|c|c|c|c|c|c|c|}
\hline Patient name & Ip no./ag e & \begin{tabular}{|c|}
$\begin{array}{c}\text { Operat ed } \\
\text { area }\end{array}$ \\
\end{tabular} & Indication & \begin{tabular}{|c|} 
Intra op \& post \\
op com plica tion \\
\end{tabular} & $\begin{array}{l}\text { Com } \\
\text { reso } \\
\end{array}$ & $\begin{array}{l}\text { mplai nt } \\
\text { oluti on }\end{array}$ & $\begin{array}{l}\text { Econom } \\
\text { ic effect }\end{array}$ & \multicolumn{2}{|c|}{$\begin{array}{l}\text { worki ng } \\
\text { days lost }\end{array}$} & \multicolumn{2}{|c|}{\begin{tabular}{|c|} 
Failur e to remo \\
ve impla nt
\end{tabular}} & Reas on \\
\hline Shivu & $3146 / 25$ & Left femur & Patient demand & - & & - & 8000 & \multicolumn{2}{|c|}{6} & \multicolumn{2}{|c|}{-} & - \\
\hline Raghu & $3567 / 40$ & \begin{tabular}{|l|} 
Tibia \\
\end{tabular} & Pain & - & & yes & 5000 & \multicolumn{2}{|l|}{6} & & - & - \\
\hline Mahadevam ma & $4739 / 45$ & clavicle & Pain & - & & Yes & 5000 & \multicolumn{2}{|l|}{5} & & - & - \\
\hline Ravi & $3969 / 22$ & Clavicle & Patient demand & - & & - & 5000 & \multicolumn{2}{|l|}{3} & & - & - \\
\hline Gopal & $9482 / 35$ & Tibia & Infected & - & & Yes & 5000 & \multicolumn{2}{|l|}{7} & & - & - \\
\hline Madhu & $4261 / 40$ & Tibia & Broken implant & - & & - & 8000 & \multicolumn{2}{|l|}{7} & & - & - \\
\hline Akshay & $4856 / 27$ & Femur & Broken plate & $\begin{array}{l}\text { Scre W Head Was } \\
\text { Roun Ded }\end{array}$ & & Yes & 5000 & \multicolumn{2}{|l|}{7} & \multicolumn{2}{|r|}{ Yes } & \begin{tabular}{|c|}
2 \\
Canc Ellou S \\
Scre Ws Left \\
\end{tabular} \\
\hline Kempanna & $5678 / 40$ & Hip & Pain & - & & Yes & 500 & \multicolumn{2}{|l|}{7} & \multicolumn{2}{|r|}{-} & - \\
\hline nanjundego wda & $6346 / 36$ & hip & Infection & - & & yes & 1300 & \multicolumn{2}{|l|}{4} & \multicolumn{2}{|r|}{-} & \\
\hline Seema & $4349 / 23$ & tibia & infection & - & & & 4500 & \multicolumn{2}{|l|}{9} & & - & - \\
\hline Anitha & $15432 / 25$ & Tibia & Elective & \multicolumn{2}{|l|}{-} & & 5000 & 7 & - & - & . \\
\hline Geetha & $14567 / 34$ & Forea Rm & Elective & \multicolumn{2}{|l|}{-} & \multicolumn{2}{|c|}{-} & 5000 & 6 & - & - & 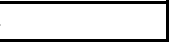 \\
\hline Kale Gowda & $15643 / 69$ & Hip & Pain & \multicolumn{2}{|l|}{-} & \multicolumn{2}{|c|}{ YES } & 6000 & 5 & - & - & . \\
\hline Prabhusw Amy & $13425 / 46$ & Femur & Infection & \multicolumn{2}{|l|}{-} & \multicolumn{2}{|c|}{ YES } & 6000 & 7 & - & - & 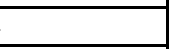 \\
\hline Sudhakar & $12456 / 42$ & Tibia & Infection & \multicolumn{2}{|l|}{-} & \multicolumn{2}{|c|}{ YES } & 5000 & 7 & - & - & 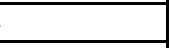 \\
\hline Bharathkum ar & $14563 / 7$ & Femur & Elective & \multicolumn{2}{|l|}{-} & \multicolumn{2}{|c|}{-} & 5000 & 6 & - & - & 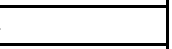 \\
\hline Krishna Swamy & $56743 / 50$ & Patell A & Pain & - & & & $\mathrm{NO}$ & 5000 & 6 & - & - & 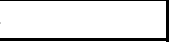 \\
\hline Javaram & $4768 / 46$ & Femur & Pain & - & & & $\mathrm{ES}$ & 5000 & 5 & - & - & 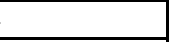 \\
\hline Boraiah & $78345 / 43$ & Humer Us & \begin{tabular}{|l|} 
Elective \\
\end{tabular} & - & & & - & 6000 & 5 & - & - & 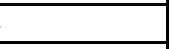 \\
\hline Krihna Gowda & $14526 / 39$ & Tibia & Broken Implant & Distal Brokr N Sc & rew & & No & 5000 & 6 & Yes & Distal Screw & Left There \\
\hline Swamy & $14265 / 36$ & Femur & Pain & - & & & $\mathrm{ES}$ & 6000 & 5 & - & - & 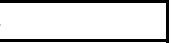 \\
\hline Mohan K & $17641 / 21$ & Tibia & Elective & - & & & - & 5000 & 5 & - & - & 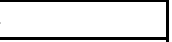 \\
\hline Kamal & $16984 / 46$ & Ulna & Patient Request & - & & & - & 5000 & 5 & - & - & 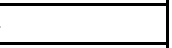 \\
\hline Alam Khan & $16289 / 50$ & Tibia & Infection & - & & & $\mathrm{ES}$ & 6000 & 7 & - & - & 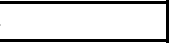 \\
\hline Najdil & $16275 / 23$ & Humer Us & Plate Exosed & - & & & - & 4000 & 7 & - & - & 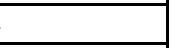 \\
\hline Kumar & $17276 / 36$ & Tibia & Infection & - & & & $\mathrm{ES}$ & 5000 & 7 & - & - & 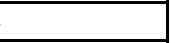 \\
\hline Anuj K & $12874 / 28$ & Radius & Patient Request & - & & & - & 4000 & 4 & - & - & 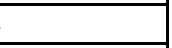 \\
\hline Dhanush & $15111 / 33$ & Forea Rm & Elective & - & & & - & 5000 & 5 & - & - & \\
\hline
\end{tabular}




\begin{tabular}{|c|c|c|l|c|c|c|c|c|c|}
\hline Ramegowd A & $17711 / 45$ & Humer Us & Implant Failure & - & RE FIXATIO N & 10000 & 6 & - & \\
\hline Sujeet & $19288 / 23$ & Forea Rm & Patient Request & - & - & 4000 & 5 & - & - \\
\hline
\end{tabular}

\section{Discussion}

It is a myth that removal of orthopedics hardware is easy as it is easier said than done. Bony overgrowth, worn out screw threads and heads, stuck nails, broken implants and ingression of bone into all possible crevices of implants. Contrary to old belief that implants that are infected are easy to remove may as well be misleading.

The incidence of implant removal in males is twice the incidence in females. The occurrence of high incidence of implant removal in males could be due to the fact that incidence of fracture is higher in males and the major indication of removal was patient request followed by infection and pain.

The information about indication and complication for implant removal in healed fractures can be seen in the current literature. Out of 30 patients only $12.5 \%$ had intra op and post op complications on implant removal which is consistent with previous studies done.

Moral is deterioration of the dictum that removal of implant is not to be taken lightly where one might have to give up the procedure. It should be explained to the patient and relatives and informed consent is mandatory.

with regard to duration of implant before removal majority of patients had implant removal within first year of insertion ${ }^{[17-20]}$. Complication rates after the removal is independent from the implant device and localization is reported between $3-20 \%$, a finding that is in accordance of our result of $12.5 \%$ [21-24] among most common complication Re fracture is the most common complication ${ }^{[25-28]}$ and it is also in accordance to our study.

Implant removal also directly affect the socioeconomic status of the patient as most of our patient are farmers and laborers and daily wages workers and they had to spend aprrox 8000 rupees for surgery and also there is working days lost which affect their daily life and also make them dependent.

\section{Conclusion}

Implant removal is one of the most commonly done surgery done in orthopedics and it is not a simple procedure. It is associated with many complications such as failure to remove implant, refracture etc. Hence a proper pre-op planning has to be done. The socioeconomic burden is high as there increase pressure on the livelihood to due to loss of working days, increased stay in hospital and implant removal cost .Most patients also has postoperative pain. Most of the implant is removed within 1 st year of their insertion.
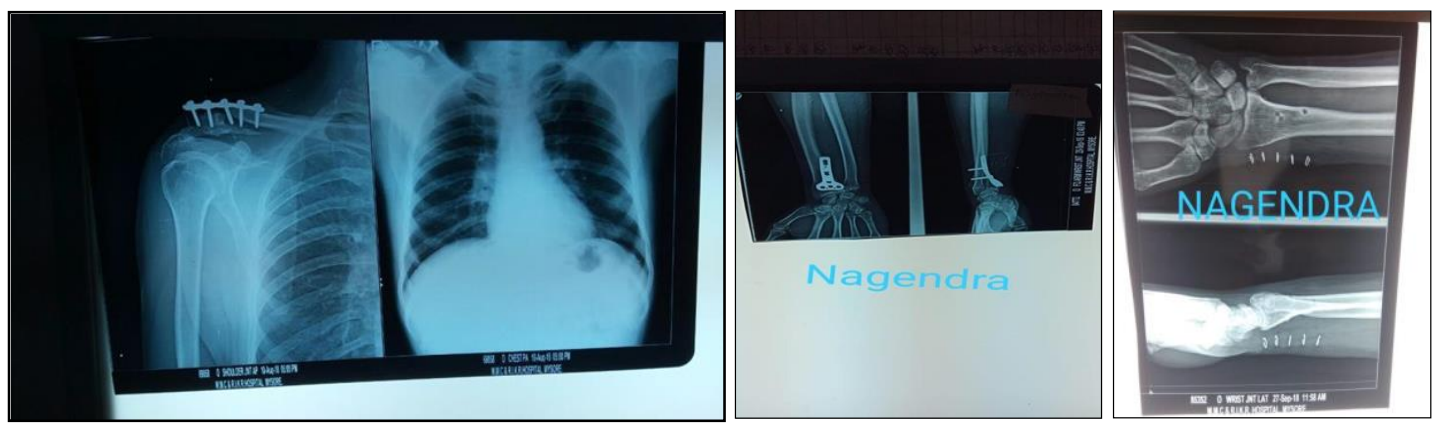

Fig 1: Xray showing clavicle plate removal Fig 2: Xray showing distal end radius plating and its removal

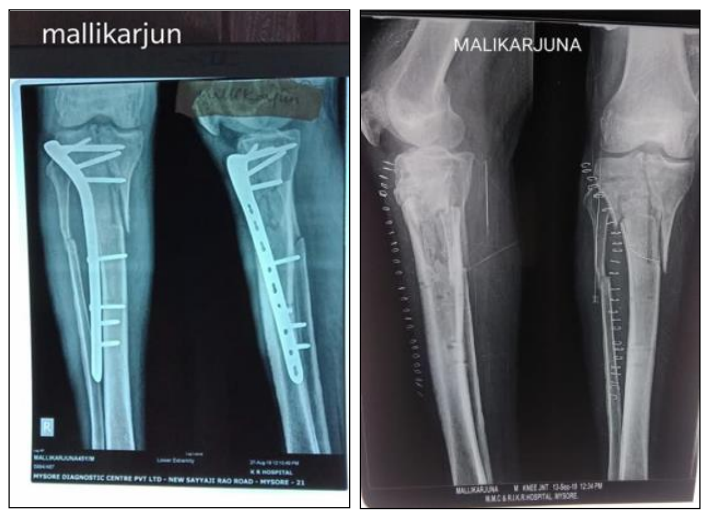

Fig 3: Xray showing PTLCP and its removal

\section{References}

1. Bostman O, Pihlajamaki $\mathrm{H}$. Routine implant removal after fracture surgery: A potentially reducible consumer of hospital resources in trauma units. Journal of TraumaInjury, Infection, and Critical Care. 1996; 41:846-849.

2. Hanson B, Van Der Werken C, Stengel D. Surgeons beliefs and perceptions about removal of orthopedics implants. BMC Musculoskeletal Disorders. 2008; 9:73.

3. Hodgson TA. The state of the art of cost-of-illness estimates. Adv Health Econ Health Serv Res. 1983; (4):129-164.
4. How to read clinical journals: VII. To understand an economic evaluation (part A). Can Med Assoc J. 1984; 130(11):1428-1434.

5. How to read clinical journals: VII. To understand an economic evaluation (part B). Can Med Assoc J. 1984; 130(12):1542-1549.

6. Rothfuss J, MauW, Zeidler $\mathrm{H}$ et al. Socioeconomic evaluation of rheumatoid arthritis and osteoarthritis: a literature review. Semin Arthritis Rheum. 1997; 26(5):771-77.

7. Seibert FJ, Puchwein P, Lanz P, Tanzer K, Clement HP. 
Femoral neck fractureafter removal of PFNA-blade case report and review of the literature. Injury Extra. 2009; 40:240-1.

8. Hesse B, Gaechter A. Complications following the treatment of trochantericfractures with the gamma nail. Arch Orthop Trauma Surg. 2004; 124:692-8.

9. Shaer JA, Hileman BM, Newcomer JE. Femoral neck fracture following hardwareremoval. Orthopedics. 2012; 35:e83-7.

10. Shaer JA, Hileman BM, Newcomer JE. Femoral neck fracture following hardwareremoval. Orthopedics. 2012; 35:e83-7.

11. Beaupre GS, Csongradi JJ. Refracture risk after plate removal in the forearm. J Orthop Trauma. 1996; 10:8792.

12. Mendez AA, Joseph J, Kaufmann EE. Stress fractures of the femoral neck fol-lowing hardware removal from healed intertrochanteric fractures. Orthopedics. 1993; 16:822-5

13. Mendez AA, Joseph J, Kaufmann EE. Stress fractures of the femoral neck fol- lowing hardware removal from healed intertrochanteric fractures. Orthopedics. 1993; 16:822-5

14. Shaer JA, Hileman BM, Newcomer JE. Femoral neck fracture following hardwareremoval. Orthopedics. 2012; 35:e83-7.

15. Beaupre GS, Csongradi JJ. Refracture risk after plate removal in the forearm. J Orthop Trauma. 1996; 10:8792.

16. Boestmann O, Pihlajamäki H. Routine implant removal after fractures surgery: apotentially reducible consumer of hospital resources in trauma units. J Trauma. 1996; 41:846-9.

17. Dannoehl C. Metal implants of the coxal femur in the elderly patient should not be removed. Aktuelle Traumatol. 1998; 19:180-2.

18. Boerger TO, Patel G, Murphy JP. Is routine removal of intramedullary nailsjustified? Injury. 1999; 30:79-81.

19. Brown OL, Dirschl DR, Obremskey WT. Incidence of hardware related pain andits effect on functional outcomes after open reduction and internal fixation ofankle fractures. J Orthop Trauma. 1993; 15:271-4.

20. Sanderson PL, Ryan W, Turner PG. Complications of metalwork removal. Injury. 1992; 23:29-30.

21. Hora K, Vorderwinkler KP, Vecsei V, Gaebler C. Intramedullary nail removal inthe upper and lower limbs. Should we recommend this operation. Unfallchirurg. 2008; 111:599-601 [603-605].

22. Kukla C, Pichl W, Prokesch R. Femoral neck fractures after removal of thestandard gamma interlocking nail: a cadaveric study to determine factorsinfluencing the biomechanical properties of the proximal femur. J Biomech. 2001; 34:1519-26.

23. Hesse B, Gaechter A. Complications following the treatment of trochantericfractures with the gamma nail. Arch Orthop Trauma Surg. 2004; 124:692-8.

24. Mendez AA, Joseph J, Kaufmann EE. Stress fractures of the femoral neck fol-lowing hardware removal from healed intertrochanteric fractures. Orthopedics. 1993; 16:822-5. 